Article

\title{
Listeria Monocytogenes Biofilm Removal Using Different Commercial Cleaning Agents
}

\author{
Annette Fagerlund, Even Heir, Trond Møretrø and Solveig Langsrud *(1) \\ Nofima, Norwegian Institute of Food, Fisheries and Aquaculture Research, 1433 Ås, Norway; \\ annette.fagerlund@nofima.no (A.F.); even.heir@nofima.no (E.H.); trond.moretro@nofima.no (T.M.) \\ * Correspondence: solveig.langsrud@nofima.no
}

Received: 17 December 2019; Accepted: 10 February 2020; Published: 12 February 2020

check for updates

\begin{abstract}
Effective cleaning and disinfection (C\&D) is pivotal for the control of Listeria monocytogenes in food processing environments. Bacteria in biofilms are protected from biocidal action, and effective strategies for the prevention and removal of biofilms are needed. In this study, different C\&D biofilm control strategies on pre-formed L. monocytogenes biofilms on a conveyor belt material were evaluated and compared to the effect of a conventional chlorinated, alkaline cleaner (agent A). Bacterial reductions up to $1.8 \mathrm{log}$ were obtained in biofilms exposed to daily C\&D cycles with normal user concentrations of alkaline, acidic, or enzymatic cleaning agents, followed by disinfection using peracetic acid. No significant differences in bactericidal effects between the treatments were observed. Seven-day-old biofilms were more tolerant to C\&D than four-day-old biofilms. Attempts to optimize biofilm eradication protocols for four alkaline, two acidic, and one enzymatic cleaning agent, in accordance with the manufacturers' recommendations, were evaluated. Increased concentrations, the number of subsequent treatments, the exposure times, and the temperatures of the C\&D agents provided between 4.0 and $>5.5 \log$ reductions in colony forming units (CFU) for seven-day-old L. monocytogenes biofilms. Enhanced protocols of conventional and enzymatic C\&D protocols have the potential for improved biofilm control, although further optimizations and evaluations are needed.
\end{abstract}

Keywords: cleaning; disinfection; biofilm; Listeria monocytogenes; food safety; enzymatic cleaning

\section{Introduction}

Cleaning and disinfection $(C \& D)$ in food industry premises are important to ensure microbial food quality and safety. The cleaning process removes food residues, soils, and organic matter that accumulate on surfaces during the production. In some cases, a bactericidal effect is also achieved [1]. Most commonly, alkaline foam or gel cleaning agents are used for the open cleaning of processing equipment, walls, and floors. The caustics act through the solubilization, swelling, and degradation of food soils, which aids the removal of soils from the surfaces. The cleaning agents may also contain additives such as surfactants, sequestrants, and hypochlorite, which improve wetting, degradation, and the removal of soils [2-4]. Acidic foam cleaners are used occasionally by some companies to remove mineral deposits. Fluid-processing equipment (e.g., pasteurizers) is cleaned with non-foaming alkaline and/or acidic agents, which are often used at higher concentrations and temperatures than employed during open cleaning. After cleaning, food contact surfaces (and often also floors and walls) are usually disinfected to further reduce the number of microorganisms to obtain a level that ensures the production of safe food that meets the expected shelf life [5].

The pathogen Listeria monocytogenes is frequently found to persist in food processing plants despite thorough and regular C\&D [6-8]. It has been shown to persist in specific niches, and drains, slicers, and conveyors are common harborage sites $[9,10]$. The exact reason for this persistence is not clear, and it could be linked to both properties of the bacterium itself (e.g., growth at low temperatures, 
specific disinfectant resistance mechanisms, and biofilm production) and to the niches where it is most commonly found (difficult to reach by C\&D, humid, collecting nutrients) [6,8]. Nevertheless, sanitation is used both as a preventive and corrective action [11-13] in Listeria control programs. It is recommended to apply the recommended user concentrations, temperatures, and times set by manufacturers of $C \& D$ agents, but this approach may not be sufficient to eradicate L. monocytogenes. Fagerlund et al. [14] showed limited effects of cleaning with a regular alkaline cleaning agent followed by disinfection (several common disinfectants were applied) on L. monocytogenes established in mono- and multispecies biofilms on conveyor belts. The belt material was designed with a relatively smooth polyvinyl chloride (PVC) top layer, while the underside was an impregnated woven polyester fabric, and L. monocytogenes seemed to be trapped and protected in biofilms within the fibers on the underside of the belt. Similarly, Chaturongkasumrit et al. [15] showed that it was difficult to eliminate L. monocytogenes biofilms growing on a polyurethane conveyor belt material by cleaning with an alkaline foam followed by disinfection with Tego-51 (an amphoteric disinfectant). The efficacy was poorer on worn belt materials, which had rougher surfaces. They showed that a slightly better reduction could be obtained by doubling the concentrations of chemicals, but a total eradication of L. monocytogenes was not achievable through a regular C\&D regime. Indeed, most studies have found that regular $C \& D$ agents are not able to remove neither laboratory nor industrial biofilms without applying shear stress, elevated temperatures, and/or an increased holding time (see e.g., [1,16-20]). However, there are some exceptions. For example, Reynisson et al. [21] studied laboratory biofilms produced by a fish bacterial flora and concluded that the biofilms were eliminated under regular C\&D concentrations and temperatures, and they suggested that the industry could reduce concentrations.

In a «seek \& destroy» strategy to combat L. monocytogenes in the food production environment, it has been suggested to use heat treatment of whole equipment or parts of it to eliminate L. monocytogenes, when regular C\&D after dismantling is not sufficient [12,13]. Other alternatives were to sanitize with $70 \%$ alcohol or high concentrations of quaternary ammonium compounds (QAC) without subsequent rinsing. There are several reasons for the industry not implementing these strategies: Heat treatment is often not possible for practical reasons, ethanol cannot be used extensively for health and safety reasons, and concerns about resistance buildup or QAC transfer to food products are expressed among food producers. Another drawback of these approaches is that the soils and nutrients are not removed, and niches where L. monocytogenes can establish are therefore maintained. Enzymatic cleaning agents are available on the market and could be an option to regular alkaline foams to remove residual soil, but they are still not commonly used [22,23]. Most enzymes suggested or used as antibiofilm agents target the polymeric substances of the extracellular matrix of bacteria (see e.g., [24-30]). Therefore, the detergents and enzymes in these cleaning agents are likely to create a disruption and dispersal of biofilms that may cause more effective access for disinfectants and provide potent biofilm eradication and microbial control.

Compared with disinfectants, comparative studies on cleaning agents for removing L. monocytogenes biofilms are few, and as far as we know, the effect of commercial cleaning agents has not been investigated. Furthermore, manufacturers of $C \& D$ agents recommend approaches to remove biofilms that have not been documented in systematic studies. The aim of this work was to compare the efficacy of different recommended cleaning approaches to remove established L. monocytogenes biofilms. To simulate a worst-case scenario, we employed the same conveyor belt L. monocytogenes biofilm model system as described in Fagerlund et al. [14], where a common niche for L. monocytogenes is combined with L. monocytogenes strains that have shown persistence in the food industry, and L. monocytogenes were allowed to form biofilms for four days prior to C\&D. A typical «standard» cleaning process was compared with cleaning processes recommended for biofilm removal and curative treatment. Protocols and in-use concentrations of the cleaning agents were in accordance with the manufacturer's suggestions. A disinfection step with peracetic acid was included to simulate a complete C\&D process. 


\section{Materials and Methods}

\subsection{Bacterial Strains and Growth Conditions}

A mixture of seven L. monocytogenes strains, belonging to different phylogenetic clusters, were used as inoculum in the current study: L. monocytogenes strains (MLST sequence types in parenthesis): MF4536 (ST9), MF5376 (ST7), MF5634 (ST121), MF5377 (ST8), MF4565 (ST18), MF5630 (ST19), and MF5378 (ST394). The selected strains were the same strains as those previously used [14], which were originally isolated by Møretrø et al. [31].

Bacteria were grown in brain heart infusion (BHI) broth (Oxoid, Basingstoke, UK). Overnight cultures were grown in $5 \mathrm{~mL}$ volumes in culture tubes at $30{ }^{\circ} \mathrm{C}$ with shaking. All biofilm and growth experiments were carried out at $12^{\circ} \mathrm{C}$. For plating, RAPID'L. mono (RLM) agar plates (Bio-Rad, Oslo, Norway) and BHI agar (Oxoid, Basingstoke, UK) plates were used.

\subsection{Cleaning and Disinfection (CED) Agents}

The selected chemical cleaning agents were purchased from manufacturers in Norway with high market share and are listed in Table 1. The enzymatic cleaning agent was from another European company. The companies provided information about the following: (i) Selection of cleaning agent for regular use (cleaning agent A); (ii) Selection of cleaning agents for removal of L. monocytogenes biofilms (B1, B2, C2, Enzymatic agent); and (iii) Selection of cleaning agents and time/concentration combinations for curative cleaning (B1, B2, C1, C2, C3, Enzymatic agent). The agents were used at the minimum recommended user concentrations, unless otherwise specified. All manufacturers recommended the dismantling of equipment and thorough mechanical scrubbing, as well as relatively high temperatures $\left(45^{\circ} \mathrm{C}\right.$ or higher) for curative cleaning. All cleaning agents were freshly prepared before use. The ethanol solution was not recommended as a cleaning agent but was included, because some food processing factories use it to clean/disinfect conveyor belts before or after breaks.

Table 1. Cleaning agents used in the current study.

\begin{tabular}{|c|c|c|}
\hline Product & Recommended Use $^{1}$ & Intended Use \\
\hline Agent A & $2-5 \%$ & $\begin{array}{l}\text { Chlorinated alkaline foam cleaner for the regular } \\
\text { cleaning of open surfaces }\end{array}$ \\
\hline Agent B1 & $2-8 \%$ & $\begin{array}{l}\text { Strong alkaline foam-gel for cleaning heavily soiled } \\
\text { surfaces }\end{array}$ \\
\hline Agent B2 & $3-6 \%$ & $\begin{array}{l}\text { Chlorinated alkaline foam for the regular cleaning of } \\
\text { open surfaces }\end{array}$ \\
\hline Agent C1 & $1-10 \%$ & $\begin{array}{l}\text { Strong acidic foam cleaner for the removal of protein and } \\
\text { mineral salt fouling }\end{array}$ \\
\hline Agent C2 & $1-10 \%$ & $\begin{array}{l}\text { Acidic cleaner for the removal of protein and mineral salt } \\
\text { fouling }\end{array}$ \\
\hline Agent C3 & $1-2 \%$ & Alkaline cleaner for cleaning-in-place (CIP) \\
\hline Enzymatic agent & Two-component $(1 \%+0.2 \%), 45^{\circ} \mathrm{C}$ & $\begin{array}{l}\text { Enzymatic foam cleaner for the prevention and removal } \\
\text { of biofilms from open surfaces. Use between regular } \\
\text { cleaning and disinfection steps }\end{array}$ \\
\hline $75 \%$ ethanol & $100 \%$ & Ethanol/propanol agent for disinfection of surfaces \\
\hline
\end{tabular}

The industrial disinfectant agent used was based on peracetic acid and is referred to as «PAA». When examining normal user concentrations of sanitation agents, PAA was used at the indicated minimum user concentration, $1.5 \%$, at which the solution contains a minimum of $0.02 \%$ peracetic acid, $0.05 \%$ acetic acid, and $0.15 \%$ hydrogen peroxide. When testing potential curative treatments (see Section 2.5.3), PAA was used at 3\% concentration as the elevated disinfectant concentration, as recommended by the manufacturers. 


\subsection{Bactericidal Suspension Tests}

Overnight cultures of the seven tested L. monocytogenes strains were mixed in equal numbers, and the combined suspension was diluted to approximately $10^{8} \mathrm{CFU} \mathrm{ml}^{-1}$ in peptone water. One $\mathrm{ml}$ of the diluted culture was added directly to $9 \mathrm{~mL}$ of deionized $\mathrm{H}_{2} \mathrm{O}$ (control) or user concentrations of cleaning agents (Table 1), resulting in a final cell concentration of approximately $10^{7} \mathrm{CFU} \mathrm{ml^{-1 }}$. After $5 \mathrm{~min}, 0.5 \mathrm{~mL}$ of the suspension was transferred to $4.5 \mathrm{~mL}$ Dey-Engley (D/E) neutralizing broth (Difco, New Jersey, USA), and dilutions were plated on BHI agar plates. The tests were performed with all solutions at $12{ }^{\circ} \mathrm{C}$. The experiment was performed twice.

\subsection{Conveyor Belt Biofilm Assay}

Biofilms of L. monocytogenes were produced and harvested as described in Fagerlund et al. [14]. In brief: Overnight cultures of the seven L. monocytogenes strains were mixed in equal volumes and diluted to a final concentration of $\sim 10^{6} \mathrm{CFU} \mathrm{m}{ }^{-1}$. Inoculums of $1 \mathrm{~mL}$ were used to inoculate each coupon $(1.0 \times 1.5 \mathrm{~cm})$ of food-grade PVC conveyor belt material $(\mathrm{E} 8 / 2 \mathrm{U} 0 / \mathrm{V} 5 \mathrm{MT}$ white FDA, Forbo-Siegling Transilon, Baar, Switzerland) placed vertically in 24-well plates, so that the air/liquid interface crossed the length of the coupon. Biofilms were grown at $12{ }^{\circ} \mathrm{C}$ for 4 days before $\mathrm{C} \& \mathrm{D}$ experiments were commenced. Then, coupons were treated with C\&D on days $4,5,6$, and 7, as detailed in Section 2.5, and they were incubated in fresh $\mathrm{BHI}$ at $12{ }^{\circ} \mathrm{C}$ between treatments. The harvest of coupons was performed before and after coupons were subjected to C\&D on the first and/or last days of C\&D treatment (days 4 and 7), as described [14]: After rinsing three times in $\mathrm{H}_{2} \mathrm{O}$ to remove nonadherent bacteria, coupons were vortexed with glass beads and sonicated $(40 \mathrm{kHz}, 10 \mathrm{~min}$, Branson 3510, Bransonic Ultrasonic Corporation, Soest, The Netherlands). Then, dilutions of suspended bacteria were plated on BHI or RLM agar plates and incubated for 2 to 3 days at $30^{\circ} \mathrm{C}$ and $37^{\circ} \mathrm{C}$, respectively.

\subsection{CED Treatment of Biofilms}

The different C\&D treatments employed in the current study are illustrated in Figure 1. 
(a)

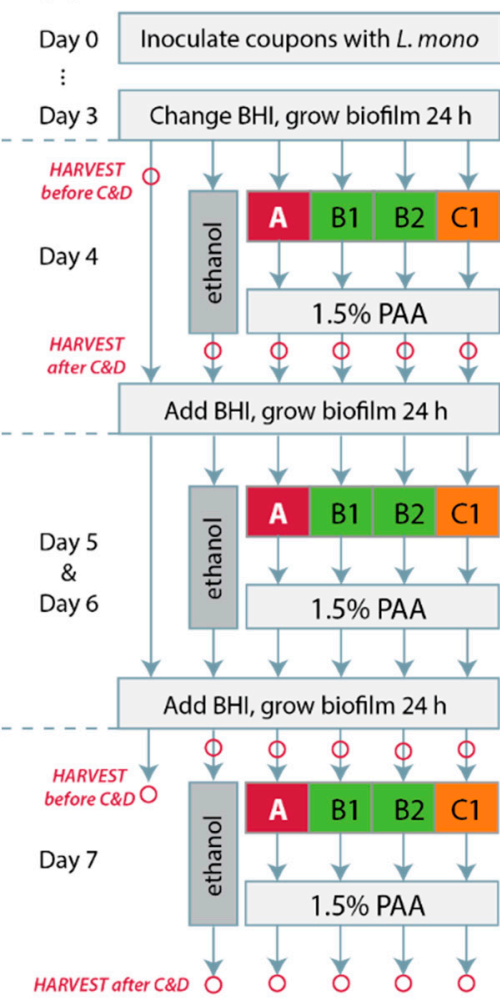

(b)

Day 0 Inoculate coupons with L. mono

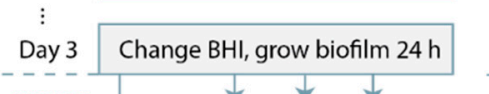

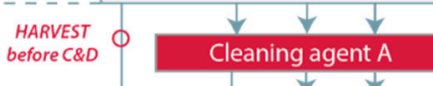

Day 4

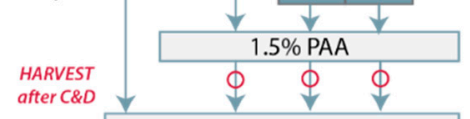

Add BHI, grow biofilm $24 \mathrm{~h}$

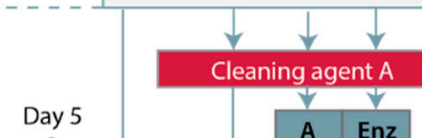

\&ay 6

Day 6

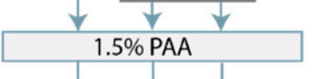

Add BHI, grow biofilm $24 \mathrm{~h}$

HARVEST

HARVEST
before C\&D

dd BHI, grow biofilm $24 \mathrm{~h}$

Day 7

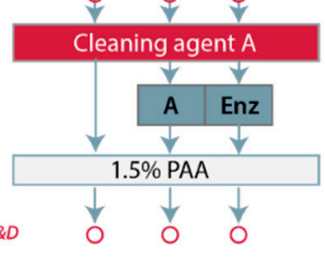

(c)

Day 0 Inoculate coupons with L. mono

Day 3 Change BHI, grow biofilm $24 \mathrm{~h}$



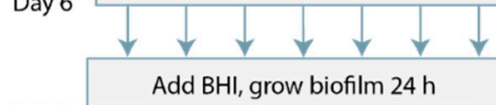
$\downarrow$
Cleaning agent $\mathrm{A}$ HARVEST
before C\&D
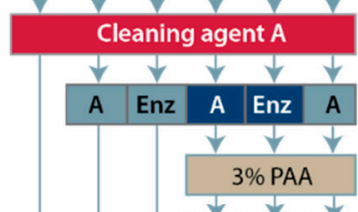

Day 7

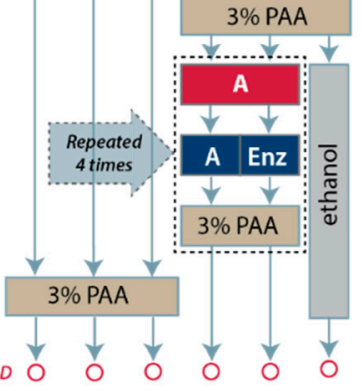

Day 0 Inoculate coupons with L. mono

Day 3 Change BHI, grow biofilm $24 \mathrm{~h}$

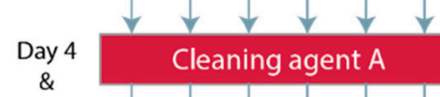

$\&$

Day 5

\&ay 6 $\downarrow \downarrow \downarrow$

$\downarrow \downarrow \downarrow \downarrow \downarrow \downarrow \downarrow$ Add BHI, grow biofilm $24 \mathrm{~h}$


HARVEST O before C\&D $O$ Cleaning agent $A$

Day 7 $40 \% 40 \% \quad 20 \%$



Figure 1. Diagrams illustrating the applied cleaning and disinfection $(C \& D)$ treatments. Each arrow represents the step in the protocol where coupons were rinsed three times in $\mathrm{H}_{2} \mathrm{O}$. Red circles indicate the steps where coupons were harvested for the determination of colony forming units (CFU) coupon ${ }^{-1}$. For steps involving cleaning agent $\mathrm{A}$, red boxes indicate incubation for $10 \mathrm{~min}$ at room temperature (RT), while blue boxes indicate incubation for 30 min with cleaning solution pre-heated to $45^{\circ} \mathrm{C}$, and incubation either at (b) RT or (c) $45^{\circ} \mathrm{C}$. For additional details, see the main text. (a) Standard C\&D treatment described in Section 2.5 .1 and employed in the experiment shown in Figure 2. (b) C\&D biofilm treatment with the enzymatic cleaning agent described in Section 2.5.2 and Figure 3. (c) Reinforced treatment with cleaning agents, see Section 2.5.3 and Figure 4a. The cleaning steps shown in light blue and dark blue boxes («A» and «Enz») represent identical treatments; different coloring (light/dark blue) is employed to coordinate with the colors used in Figure 4a. (d) C\&D with higher concentrations of chemical cleaners, see Section 2.5 .3 and Figure $4 \mathrm{~b}$. 


\subsubsection{Standard C\&D Biofilm Treatment}

The standard C\&D biofilm treatment (Figure 2) was performed as follows: Coupons were rinsed three times in approximately $10 \mathrm{~mL}$ of sterile deionized $\mathrm{H}_{2} \mathrm{O}$ (in 15-mL Falcon tubes) to remove nonadherent bacteria and placed vertically in wells of a clean 24-well tray. Then, a chemical cleaning agent (either agent A, B1, B2, or C1) was applied to each well in the form of foam (as intended by the manufacturers; produced in foam pump bottles from Sunvita, Bergen, Norway). The coupons were incubated in cleaning agent for $10 \mathrm{~min}$ before coupons were rinsed as before in $\mathrm{H}_{2} \mathrm{O}$ and placed in a second clean $24-w e l l$ plate. Then, the wells were filled with $1.5 \%$ peracetic acid-based disinfection agent (PAA) foam, and the coupons were incubated $5 \mathrm{~min}$ and finally rinsed in $\mathrm{H}_{2} \mathrm{O}$ again. Coupons treated in parallel with $75 \%$ ethanol were processed as follows: These were subjected to the first and last rinse in $\mathrm{H}_{2} \mathrm{O}$ (as above), but they were incubated in ethanol while the coupons processed in the same experiment were subjected to C\&D treatment (10 min in cleaning agent, rinse, $5 \mathrm{~min}$ in PAA). Control coupons were rinsed three times with $\mathrm{H}_{2} \mathrm{O}$ every day. The entire experiment was performed at room temperature (RT) (approximately $20^{\circ} \mathrm{C}$ ).

\subsubsection{C\&D Biofilm Treatment with Enzymatic Cleaning Agent}

In the experiment where coupons were treated with the enzymatic cleaning agent (Figure 3), referred to as «Enzymatic agent» (Table 1), the protocol was modified as follows: All coupons were treated as described above with cleaning agent $\mathrm{A}$ and rinsed in $\mathrm{H}_{2} \mathrm{O}$. Then, coupons were either left in $\mathrm{H}_{2} \mathrm{O}$, treated with either 2\% agent A or normal user concentrations of Enzymatic agent, both pre-heated to $45^{\circ} \mathrm{C}$ and applied as foam. Incubation was performed for $30 \mathrm{~min}$ at RT before rinsing and treatment with PAA, as described in Section 2.5.1.

\subsubsection{Curative C\&D Biofilm Treatment}

In experiments to test curative treatments, biofilms were allowed to develop for 4 days, as before, and then - on days 4, 5, and 6 - coupons were subjected to treatment with $2 \%$ agent $\mathrm{A}$ for $10 \mathrm{~min}$ followed by $1.5 \%$ PAA for $5 \mathrm{~min}$, as described in Section 2.5.1. On day 7, alternative cleaning agent treatments were tested, followed by treatment with PAA at an increased concentration (3\%). In the reinforced treatment with the Enzymatic agent (Figure 4a), the same conditions as in the Enzymatic agent assay described above (Section 2.5.2) were used, except that the $30 \mathrm{~min}$ incubation step was performed in a closed container at $45{ }^{\circ} \mathrm{C}$, and PAA was used at a concentration of $3 \%$. Both one round and five successive rounds of the protocol were performed, as well as one round followed by treatment with $75 \%$ ethanol for the duration of the parallel experiment where coupons were subjected to an additional four rounds of the protocol.

In treatments with higher concentrations of cleaners (Figure $4 \mathrm{~b}$ ), the following cleaning steps were compared: Submersion in $40 \%$ agent B1 or B2 for $30 \mathrm{~min}$ at RT, submersion in $20 \%$ agent C 3 for $30 \mathrm{~min}$ followed by rinsing in $\mathrm{H}_{2} \mathrm{O}$ as before and incubation either in $10 \%$ foam of agent $\mathrm{C} 1$ or submerged in $10 \%$ agent $\mathrm{C} 2$. All coupons were finally rinsed and treated with $3 \%$ PAA as before.

\subsection{Statistical Calculations}

Estimates for the mean and variance (standard error of mean of two or three biological experiments) for each treatment plotted in the figures were calculated from the $\log _{10}$-transformed values of CFU per coupon (or reduction in CFU per coupon). The total counts used were averages of technical replicates, when included. One-way ANOVA and Tukey's pairwise comparison were used to test for differences between pairs and groups of treatment means. One-sample t-tests were used to test whether $\log _{10}$ reductions were significantly different from 0 . Statistical tests were performed in Minitab v18.1 (Minitab Ltd, Coventry, England). 


\section{Results and Discussion}

\subsection{Suspension Tests to Examine Tolerance of Planktonic Cells to the Tested Cleaning Agents}

A panel of chemical cleaning agents intended for use in the food industry and recommended by their manufacturers for use against biofilms of L. monocytogenes were obtained for testing (Table 1). To examine whether the employed L. monocytogenes strains had a specific tolerance toward the employed cleaning agents, bactericidal suspension tests were performed on the L. monocytogenes mixture, using the recommended minimum user concentrations for each product (Table 2). We have previously shown that the bacterial reductions were $5 \log$ units after the exposure of these L. monocytogenes strains to the employed concentration of PAA disinfectant $(1.5 \%)$ for $5 \mathrm{~min}$ at $12{ }^{\circ} \mathrm{C}$ [14].

The bacterial reductions were $>5 \mathrm{log}$ units after exposure to the tested concentrations of the chlorinated alkaline cleaners (agents A and B2) for $5 \mathrm{~min}$ at $12{ }^{\circ} \mathrm{C}$, but they were only between 1 and 2 log units for the strong alkaline cleaner (B1), while the cleaning-in-place (CIP) alkaline cleaner (C3) gave intermediate results. Since the exact composition of the agents is not known, it is not possible to explain the differences, but chlorine likely contributes to the high bactericidal effect observed, although chlorine has less bactericidal activity at high $\mathrm{pH}$ [2].

More than $5 \log$ reduction was also obtained for the strong acidic cleaner (C1), but almost no bactericidal activity was found for the regular acidic cleaner (C2), although the $\mathrm{pH}$ was similar for both products. The enzymatic agent also showed listericidal effects, although the $\mathrm{pH}$ was relatively neutral, and the enzymes used were not expected to show listeridal activity according to the manufacturer's information. Again, the exact compositions of the cleaners are not known, so the differences may be due to additives.

Table 2. Bactericidal suspension test results (cleaning agents).

\begin{tabular}{cccc}
\hline Product & Concentration & Bactericidal Suspension Test Results (log reductions) $^{\mathbf{1}}$ & $\mathbf{p H}$ \\
\hline Agent A & $2 \%$ & $>5.3,>5.4$ & 12.1 \\
Agent B1 & $2 \%$ & $1.9,1.1$ & 12.5 \\
Agent B2 & $3 \%$ & $>5.3,>5.4$ & 12.7 \\
Agent C1 & $1 \%$ & $>5.3,>5.4$ & 2.0 \\
Agent C2 & $1 \%$ & $0.6,0.5$ & 1.9 \\
Agent C3 & $1 \%$ & $3.8,>5.4$ & 12.2 \\
Enzymatic Agent & $1 \%+0.2 \%$ & $3.9,4.0$ & 7.8 \\
\hline${ }^{1}$ Results from both biological replicates are shown. For the control sample without added cleaning agent, 7.3 and \\
7.4 log CFU ml ${ }^{-1}$ was obtained.
\end{tabular}

\subsection{Application of Chemical Cleaning Agents to Biofilms at Normal In-Use Concentrations}

The efficacy of cleaning agents was tested on biofilms formed from a mixture of seven different strains of L. monocytogenes on PVC conveyor belt material coupons, as previously described [14]. The efficacy was compared with the conventional chlorinated alkaline cleaning agent (agent A, Table 1), exposure to a $75 \%$ ethanol solution, and with merely rinsing the coupons each day in water. Treatments with cleaning agents, which were employed at the recommended user concentrations, were followed by rinsing and treatment with a foaming peracetic acid-based disinfection agent (PAA). In the initial experiment, the conveyor belt biofilm model was used to compare the use of cleaning agent A with two additional alkaline cleaning agents-a strong alkaline cleaner (agent B1), a chlorinated alkaline cleaner (B2) — as well as a strong acidic cleaner (C1) (Table 1). The results are shown in Figure 2.

After the initial 4 days of biofilm development, the cell densities in the L. monocytogenes biofilms reached approximately $1 \times 10^{7} \mathrm{CFU}$ per coupon $\left(3 \mathrm{~cm}^{2}\right.$ surface area) (Figure 2a, bar: day 4$)$. Next, coupons were subjected to daily cycles of C\&D, or daily incubation in $75 \%$ ethanol, for three days. Control coupons were rinsed with sterile $\mathrm{H}_{2} \mathrm{O}$ every day. Then, coupons were sampled on day 7 after allowing $24 \mathrm{~h}$ of regrowth after the last treatment cycle (with $\mathrm{C} \& \mathrm{D}$, ethanol, or $\mathrm{H}_{2} \mathrm{O}$, respectively). Treatment with ethanol resulted in significantly lower cell density on each coupon compared with rinsing in $\mathrm{H}_{2} \mathrm{O}$ or treatment with $\mathrm{C} \& \mathrm{D}$ using one of the four tested cleaning agents $(p \leq 0.05$ for all 
relevant two-way comparisons) (Figure 2a). Interestingly, the differences in biocidal activity between cleaning agents as shown in the biocidal suspension tests (Table 2) did not seem to matter, as the effect toward the L. monocytogenes biofilms was not significantly lower for agent B1 than for the other tested agents. Probably, the main effect was biofilm removal and not a killing effect in biofilms, as biofilms are generally very resistant to biocidal activity [8]. Overall, no significant differences were detected between any of the other conditions tested. Thus, none of the four C\&D regimes tested were able to reduce the total amount of $L$. monocytogenes biofilm on the conveyor belt materials present $24 \mathrm{~h}$ after the last C\&D treatment.
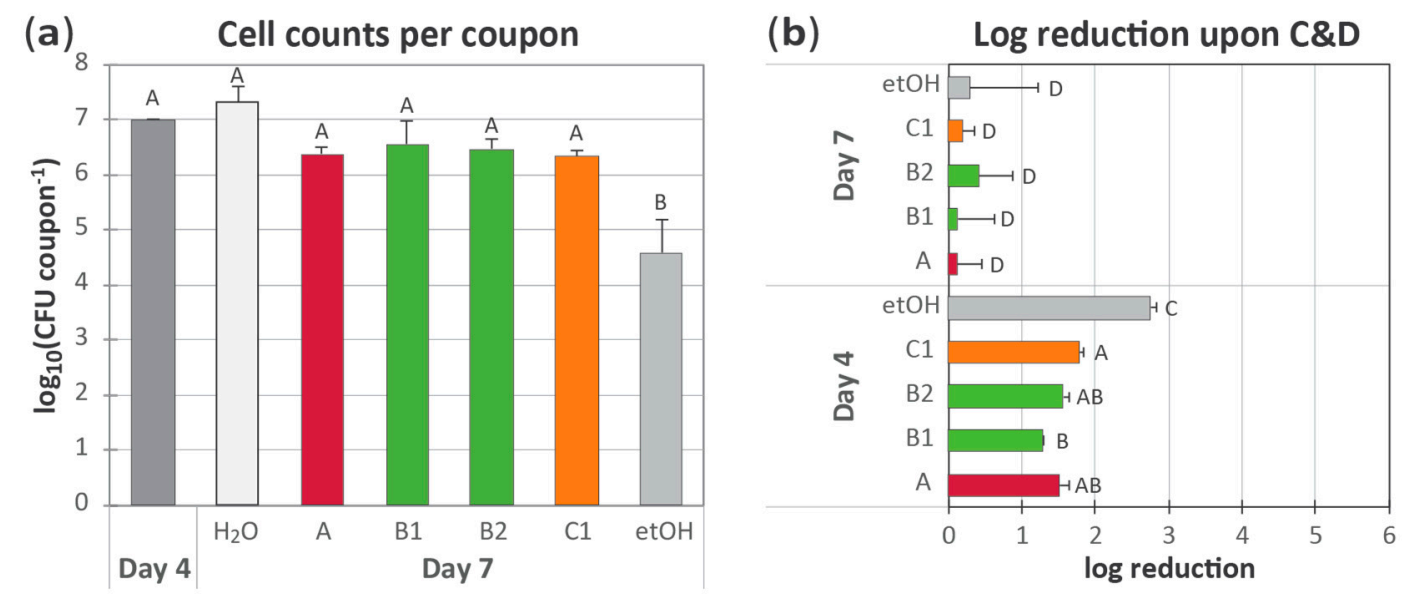

Figure 2. Biofilms of L. monocytogenes were allowed to develop undisturbed on conveyor belt coupons until day 4. Then, coupons were treated each day with either (i) rinsing in $\mathrm{H}_{2} \mathrm{O}$, (ii) cleaning with cleaning agents $\mathrm{A}(2 \%), \mathrm{B} 1(2 \%), \mathrm{B} 2(3 \%)$, or C1 $(1 \%)$, followed by disinfection with a peracetic acid (PAA)-based disinfection agent $(1.5 \%)$, or (iii) incubation in $75 \%$ ethanol (etOH). (a) Total counts of L. monocytogenes in conveyor belt biofilms prior to treatments (Figure 1a; day 4) and after three consecutive days of treatments followed by $24 \mathrm{~h}$ of regrowth in brain heart infusion (BHI) culture medium (Figure 1a; day 7). (b) Tolerance of biofilms to treatment regimes, shown as the log reductions in bacterial counts upon C\&D (or ethanol) treatment on days 4 and 7. For each experiment, the mean values of two replicates with standard errors of the means are shown. Different letters indicate a statistically different effect of treatments (confidence level 95\%); in (b), data for days 4 and 7 were considered separately in the statistical analysis.

When the total numbers of CFU per coupon before and after C\&D (or ethanol) treatment were compared (Figure 2b), the results showed that overall, the treatments had significantly lower effect on day 7 compared with on day $4(p<0.001)$. The day 7 coupons had been subjected to three prior days of treatments, while the day 4 coupons had not. Notably, on day 7, none of the C\&D (or ethanol) treatments were able to reduce the amount of $L$. monocytogenes biofilm present on the conveyor belt coupons (one-sample t-tests with $\mathrm{H}_{0}: \mu=0$ gave $p \geq 0.5$ for all treatments). However, when incubation in $75 \%$ ethanol was applied on untreated biofilms on day 4 , almost a 3 log reduction in cell density on the coupons was obtained. This was a significantly increased reduction compared with that obtained with the four tested C\&D treatments, which resulted in between 1.3 and $1.8 \log$ reduction in biofilm on the coupons. Thus, the L. monocytogenes biofilms became tolerant toward treatment with all tested C\&D regimes and with ethanol treatment within the course of this experiment. We previously observed similar results where the initial tolerance and tolerance development observed were not likely to be a result of specific resistance mechanisms but rather a combination of the attributes of the conveyor belt and broad-spectrum mechanisms linked to the biofilm mode of growth [14]. Others have reported from minor to several log reductions of L. monocytogenes in biofilms after C\&D in conditions reflecting those found in food processing environments [32,33]. Further studies are needed to rule out whether the various tolerance effects observed are due to the age of the biofilm, adaptive responses of 
L. monocytogenes biofilm cells obtained through exposure to the C\&D agents, or a combination of both biofilm age, previous exposure to the $C \& D$ agents, or other factors.

\subsection{Examining the Efficacy of Enzyme-Based Cleaning for Biofilm Removal}

According to the user instructions, the enzymatic foaming cleaning agent should be applied for $30 \mathrm{~min}$ at $45^{\circ} \mathrm{C}$, between the regular $\mathrm{C} \& \mathrm{D}$ step, to remove biofilms. The efficacy of this treatment in the L. monocytogenes conveyor belt biofilm model was tested and compared with two treatment protocols employing C\&D treatment using only the conventional cleaning agent A (Table 1): In all three protocols, coupons with biofilm were rinsed and cleaned with room-temperature solution of agent $\mathrm{A}$ as before (for $10 \mathrm{~min}$ at $\mathrm{RT}$ ), followed by rinsing three times in $\mathrm{H}_{2} \mathrm{O}$. Then, one coupon was left standing in the last rinse water, while the other two coupons were subjected to a second step of cleaning (30 $\mathrm{min})$ : one coupon was treated with the Enzymatic agent, while the other was treated with agent $\mathrm{A}$; both were pre-heated to $45^{\circ} \mathrm{C}$. After rinsing, all three coupons were subjected to disinfection with PAA as described above. Although the optimum temperature for the Enzymatic agent is $45^{\circ} \mathrm{C}$, in practice, the foam-based cleaning of food industrial surfaces and equipment at $45^{\circ} \mathrm{C}$ is likely both difficult (as the materials may keep a temperature of $4-12^{\circ} \mathrm{C}$ and cool down the foam) and something one would want to avoid (increasing temperatures may enhance microbial growth). Therefore, while the cleaning agents had a temperature of $45^{\circ} \mathrm{C}$ at the time of application, the 30 min exposure time was performed at room temperature $\left(\sim 20^{\circ} \mathrm{C}\right)$. As before, the $\mathrm{C} \& \mathrm{D}$ procedure was performed daily for four days starting with four-day-old biofilms of L. monocytogenes, and sampling was performed on the first and last days of C\&D treatment (days 4 and 7). The results are shown in Figure 3.
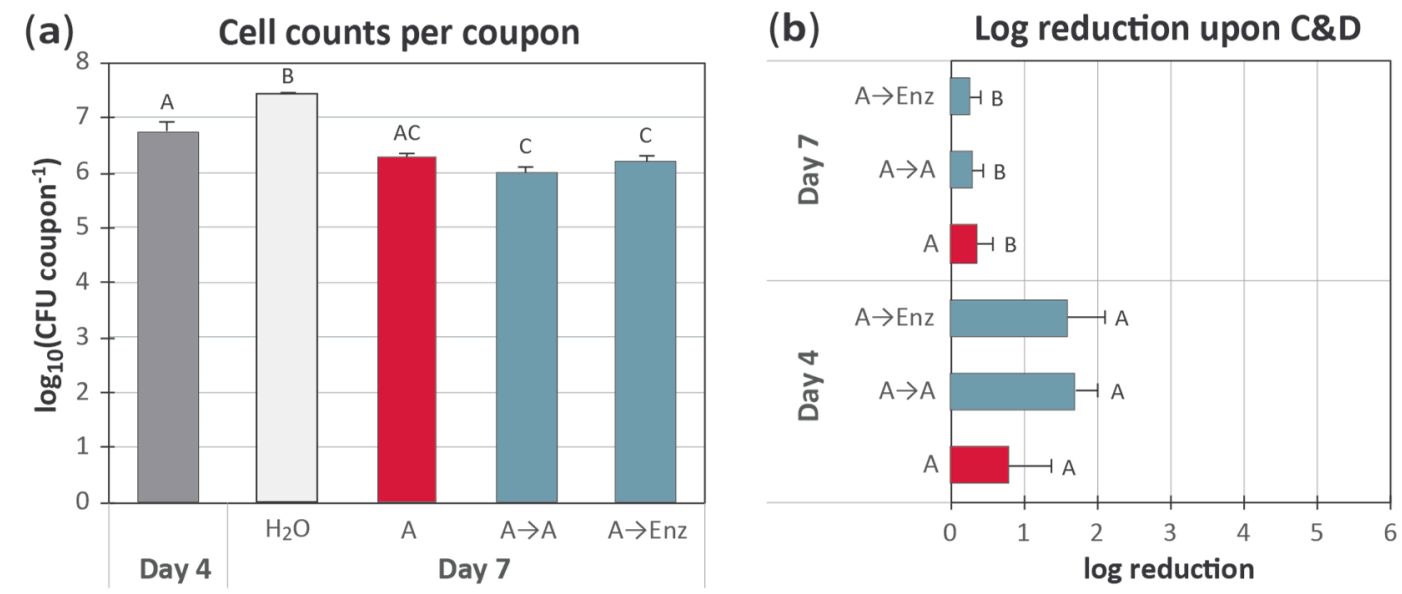

Figure 3. The four-day-old biofilms were subjected to C\&D treatments on days 4, 5, 6, and they were allowed $24 \mathrm{~h}$ of regrowth before sampling. The C\&D treatments were either (i) $2 \%$ Agent $\mathrm{A}$ for $10 \mathrm{~min}$ only (A); (ii) 2\% Agent A for $10 \mathrm{~min}$ followed by $2 \%$ Agent A at $45^{\circ} \mathrm{C}$ for $30 \mathrm{~min}$ at RT (A $\rightarrow \mathrm{A}$ ); or (iii) $2 \%$ Agent A for $10 \mathrm{~min}$ followed by an Enzymatic Agent pre-heated to $45^{\circ} \mathrm{C}$, for $30 \mathrm{~min}$ at RT (A $\rightarrow$ Enz). After these treatments, all coupons were disinfected with 1.5\% PAA. (a) Counts of L. monocytogenes in conveyor belt biofilms prior to C\&D at day 4 and day 7. (b) Tolerance of biofilms to treatment regimes. Results are based on three replicates; details are otherwise as described in the legend to Figure 2.

All three C\&D treatments resulted in significantly lower cell densities on coupons sampled after allowing $24 \mathrm{~h}$ of regrowth after the three consecutive C\&D cycles on days 4, 5 and 6 , compared with coupons that were only rinsed with sterile deionized $\mathrm{H}_{2} \mathrm{O}$ each day (Figure 3a). However, no statistically significant difference could be detected between the conventional C\&D treatment and C\&D treatments performed with an extra cleaning step employing either enzymatic or conventional cleaner (Figure 3a).

When examining the log reductions obtained by comparing the total numbers of CFU per coupon before and after $C \& D$ treatment, we obtained a similar result as in the experiment shown in Figure $2 b$ : 
All C\&D treatments had a significantly lower effect on day 7 compared to the effect on biofilms treated on day 4 of the experiment $(p=0.003$ ) (Figure $3 b$ ). In addition, as before, on day 7 , none of the C\&D treatments were able to significantly reduce the amount of L. monocytogenes biofilm present on the conveyor belt coupons ( $p \geq 0.23)$.

Furthermore, there was no significant difference between treatments observed in this experiment ( $p=0.4$ for day 4 and $p=0.9$ for day 7). Thus, under these conditions, the enzymatic cleaner containing enzymes targeting polymeric substances (EPS) of the extracellular matrix, and the conventional chlorinated alkaline cleaning agent, which acts through the unspecific degradation, wetting, and solubilization of organic matters, reduced biofilm by approximately one $\log _{10}$. To our knowledge, the effect of commercial enzymatic agents on L. monocytogenes biofilms has not been reported before. However, the results were in the same range as in two previous studies on biofilm removal using enzymes, resulting in a modest reduction of $1-2 \log _{10}$ reduction [22,34]. As stated in Section 3.2, the literature shows highly variable results for the effect of commercial alkaline cleaners on L. monocytogenes biofilms. In conclusion, disregarding the type of cleaning agent, including one extra cleaning step did not result in enhanced removal of the L. monocytogenes biofilm, and it appears not to be a solution for biofilm removal.

\subsection{Curative CED Treatments with Extreme Use of Cleaners}

The results obtained above (Figure 2; Figure 3) showed that none of the tested C\&D regimes were able to significantly reduce the level of bacteria in conveyor belt biofilms subjected to C\&D on the three previous days. It is easy to envision similar situations in a food processing facility in which a biofilm has been established and subsequently, perhaps in the face of contamination problems, is subjected to daily C\&D without obtaining the desired effect. The manufacturers of the cleaning agents were asked what action they would recommend in such a scenario. Suggestions included the application of repeated cleaning cycles and the use of increased concentrations of the chemical cleaning agents, as well as the use of more than one type of cleaning agent in succession. These suggestions were tested in the current study.

Furthermore, one of the manufacturers stressed that all parts should be allowed to completely dry between each C\&D step and that heated water $\left(35-55^{\circ} \mathrm{C}\right)$ should be used for the rinsing steps performed before the application of each cleaning agent. All manufacturers additionally suggested the inclusion of a mechanical brushing step. These approaches were not tested in the current study.

\subsubsection{Biofilm Treatment with Reinforced C\&D and Repeated C\&D Cycles}

Although the addition of one extra cleaning step did not seem to significantly increase the removal of L. monocytogenes biofilms in our tests (Figure 3), the manufacturer of the enzymatic cleaning agent recommended repeated cleaning cycles for the elimination of L. monocytogenes biofilms. Furthermore, they recommended using $45^{\circ} \mathrm{C}$ throughout the exposure time for the Enzymatic agent and doubling the concentration of the disinfectant. This approach was tested for one conventional cleaning agent and the Enzymatic cleaning agent, using the following conditions (see Section 2.5.3 and Figure 1c): Biofilm formation was initialized for 4 days as before, followed by treatment of all coupons with the same standard C\&D regime on days 4,5, and 6. This treatment consisted of cleaning with a standard chlorinated alkaline cleaning agent (agent A) followed by PAA disinfectant at 1.5\% as previously described. Then, on day 7, coupons were subjected to different C\&D protocols, as described in Section 2.5.3 and Figure 1c: (i) A protocol with a standard cleaning step (agent A, 10 min at RT) followed by $3 \%$ PAA. (ii) A protocol with the standard cleaning step, followed by reinforced cleaning with either an Enzymatic agent or conventional cleaner (agent A) (30 min with $45^{\circ} \mathrm{C}$ during incubation), and finally $3 \%$ PAA. (iii) A protocol where the entire C\&D cycle [described in ii)] was performed five times in succession. (iv) A protocol where the two-step cleaning cycle with agent A in both steps was followed by the submersion of coupons in $75 \%$ ethanol (total time for ethanol exposure approximately 3 hours). The results are shown in Figure 4 a. 
In this experiment, the highest efficacy was observed for the treatment of coupons that were subjected to two cleaning steps (one for $10 \mathrm{~min}$ at RT and one for $30 \mathrm{~min}$ at $45^{\circ} \mathrm{C}$ ) followed by incubation in $75 \%$ ethanol (Figure 4a; gray bar). Under these conditions, no bacteria were detected on $50 \%$ of the individual tested coupons, and this treatment thus gave about $5 \log$ reduction. In comparison, when a shorter ethanol treatment step was applied without prior cleaning steps and subsequent PAA treatment, 3 log reduction was obtained (Figure 2b; gray bar).

The treatment employing five successive rounds of the reinforced C\&D procedure using the standard alkaline cleaning agent $\mathrm{A}$ in both cleaning steps gave the second largest reduction. This was the only treatment (beside ethanol) that was significantly different from using regular one-step cleaning with an alkaline foam and gave above $4 \log$ reduction in CFU on coupons (Figure $4 a ; 5 \times[A \rightarrow A]$ ). In this test, one of six replicates gave a result below the detection limit.

\section{(a)}

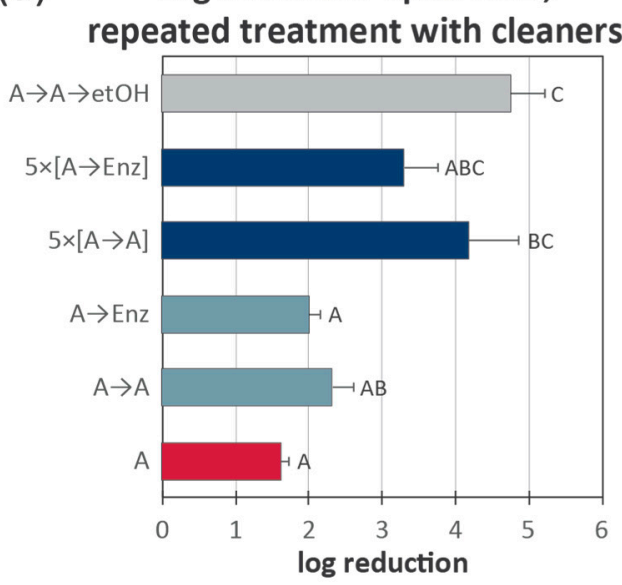

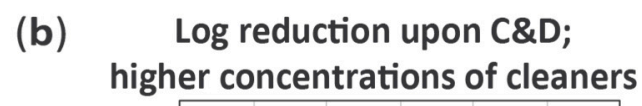

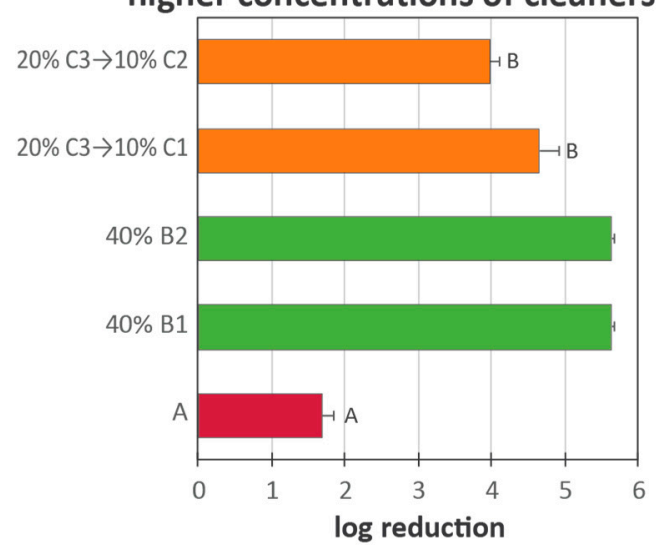

Figure 4. Tolerance of biofilms with reinforced cleaning protocols. Biofilms were allowed to develop for 4 days, and coupons were then cleaned with agent A followed by disinfection with $1.5 \%$ PAA for three consecutive days. On day 7, coupons were subjected to different treatment protocols, and the amount of L. monocytogenes remaining on coupons after treatment was compared with the number of bacteria present on the day 7 coupons that were subjected only to rinsing in $\mathrm{H}_{2} \mathrm{O}$. For details on protocols, see the main text and Figure 1c,d. (a) Bacterial reductions obtained after biofilm treatment with reinforced cleaning and repeated C\&D steps (b) Bacterial reductions obtained after biofilm treatment with high dosages of chemical cleaning agents. Experiments in (a) and (b) were performed the same time, and the results for the control treatment using standard C\&D treatment with cleaning agent $\mathrm{A}$ (column $A$, in red) is shown in both figures. The average CFU per coupon for coupons rinsed in $\mathrm{H}_{2} \mathrm{O}$ only was $1.8 \times 10^{7} \mathrm{CFU}$ coupon $^{-1}$, and the detection limit was $5.6 \mathrm{log}$ reductions. Results are based on (a) three and (b) two biological replicates, each with parallel coupons. Mean values and standard errors of the means are shown, with different letters indicating statistically different effect of treatments (confidence level 95\%); except in (b), where treatments with agents B1 and B2 reached the detection limit, and therefore, significance was not calculated.

These two treatments were significantly more effective than the control C\&D procedure using only one standard cleaning step (Figure $4 \mathrm{a}$; red bar). Five successive rounds of the reinforced C\&D procedure using the enzyme-based cleaner in the second cleaning steps (Figure $4 \mathrm{a} ; 5 \times[\mathrm{A} \rightarrow$ Enz]) gave a larger average log reduction than the standard control C\&D treatment (Figure 4a; red bar); however, the variation in performance was high, and the difference was not significantly different $(p=0.12)$. Since the cleaning efficacy of alkaline increases with temperature [2], it is tempting to speculate that the increased effect of several repeating exposures to cleaning agent A is merely a result of higher temperature and a longer exposure time to alkaline. For the combination with enzymes, the increase in exposure time and temperature was not enough to result in a significantly increased biofilm removal. 


\subsubsection{Biofilm Treatment with High Dosages of Chemical Cleaning Agents}

The use of highly increased concentrations of chemical cleaning products, along with the soaking of dismantled equipment parts in these solutions for extended periods of time, was suggested by the manufacturers as an approach to eliminate L. monocytogenes biofilms. Another advice was to use more than one type of cleaning agent. We selected to test the application of increased concentrations and incubation times of cleaning agents in an attempt to achieve a more efficient removal of biofilm in our model. For an overview of the tested protocols, see Section 2.5.3 and Figure 1d.

For testing the alkaline foaming agents B1 and B2, coupons were submerged for $30 \mathrm{~min}$ in $40 \%$ solution of each cleaning agent. This concentration is 5-7 times higher than the highest indicated user concentrations when the products are employed in regular cleaning. According to the manufacturer, this strategy had not been tested in situ before, as the cleaners were relatively new. In line with the results from an early study on L. monocytogenes biofilm eradication [35], the manufacturer of C1, C2, and C3 had experienced a good effect of increased temperatures, concentrations, and the sequential use of alkali and acid cleaners in problem solving. An initial 30 min soaking step with a $20 \%$ solution of an alkaline clean-in-place (CIP) detergent cleaner, agent C3, was used prior to treatment with the acidic cleaner (Table 1). Thus, agent $\mathrm{C} 3$ was used at 10 times the normal user concentration for this product. Then, following rinsing, we tested both the cleaning agent $\mathrm{C} 1$, applied as foam, and a different non-foaming product intended for CIP cleaning: agent C2 (Table 1). Agents C1 and C2 were used at $10 \%$ concentration, which is the highest recommended user concentration, and it was allowed to act for $40 \mathrm{~min}$ before rinsing. To be able to compare results across experiments, the conditions were otherwise as described above: Biofilms were developed for four days and then subjected to a standard C\&D procedure using agent $\mathrm{A}$ and $1.5 \%$ PAA on days 4 to 6 . After completion of the indicated cleaning steps on day 7, coupons were disinfected with 3\% PAA. The results are shown in Figure $4 \mathrm{~b}$.

The use of higher cleaning agent concentrations, combinations, and extended exposure times (soaking) of the biofilms to the cleaning agents followed by 3\% PAA disinfection showed significant $(p<0.003)$ effects and increased the listericidal effects by between 2 and 4 log reductions compared to the control C\&D with $2 \%$ agent $\mathrm{A}$ and $3 \%$ PAA (Figure $4 \mathrm{~b}$ ). The experiment was performed at $\mathrm{RT}$ and not at $35-55^{\circ} \mathrm{C}$ as the manufacturer recommended, and one would expect an even larger reduction with higher temperature. Arizcun et al. [35] found that the reduction of L. monocytogenes biofilm increased by more than 4 logs by increasing the temperature from 20 to $55^{\circ} \mathrm{C}$ in a sequential cleaning experiment with alkaline and acetic acid. For the treatment of coupons with $40 \%$ solutions of cleaning agents, no bacteria were detected on the tested coupons after C\&D treatment, both with the strong alkaline foam gel (B1) and the chlorinated alkaline foam B2 (Figure 4b; green bars) (the detection limit was a log reduction of 5.6).

\subsection{Overall Comparison of Cleaning Approaches}

In the present study, model L. monocytogenes biofilms were allowed to develop on a conveyor belt material with a woven underside, which is a well-known niche where L. monocytogenes may persist and survive $C \& D$ in industrial settings. The obtained results supported the experiences from the industry, as the recommended $C \& D$ protocols with conventional and enzymatic cleaning agents showed limited effects against $L$. monocytogenes in biofilms. In addition, repeating the $C \& D$ cycle had limited effect, and it can not be regarded as cost effective in a practical situation.

The manufacturers of the C\&D agents stressed that mechanical action is needed to remove biofilms, but we chose to not include any significant form of mechanical cleaning and shear forces in the model system. It is likely that higher bacterial reductions would have been observed if scrubbing or rinsing with high-pressure sprays had been applied. However, considering that biofilm formation and bacterial persistence primarily occur on sites and niches in food processing equipment and surfaces where brushing or mechanical forces are not effective due to limited availability or poor hygienic design issues, the model system applied seems relevant. Another factor is the likely higher diversity, complexity, and variations in microbial biofilm structure existing in the food processing environments 
relative to those reflected in the present study. Here, monospecies biofilms of L. monocytogenes formed on a single substrate under defined conditions were used. Biofilms produced by L. monocytogenes are complex structures and consist of both polysaccharides, teichoic acid, proteins, and extracellular DNA (eDNA), which is something that may explain why they may be more difficult to eradicate than common food soils or biofilms formed by other bacteria $[3,10,14]$.

High concentrations and extended exposure times of the cleaning and/or disinfection agents were needed to eradicate L. monocytogenes biofilms from the conveyor belt in the absence of mechanical action. These conditions were extreme compared to normal in-use conditions, and issues such as an increased use of time, costs for chemicals, health issues, and the sensitivity of equipment and machines to high concentrations of chemicals must be considered before implementing such procedures. An effective alternative to excessive cleaning was using an alcohol disinfectant after a thorough cleaning with a caustic cleaning agent. This approach can be considered as an alternative curative treatment of L. monocytogenes house strains.

In addition to the effect on biofilms and removing soil, environmental and health effects also must be taken into consideration when choosing cleaning agents. The exact composition of the commercial agents was not known, and an investigation of the safety of the products is beyond the scope of this paper. However, according to the information provided by the manufacturers in the product safety data sheets, all cleaning agents tested, except for the enzymatic (which were classified as irritating to skin) contained chemicals that cause serious skin and eye damage. The enzymatic agent could cause asthma symptoms. All alkaline cleaning agents were classified as very toxic to aquatic life with long-lasting effects, which was due to their content of alkali, hypochlorite, and/or alkyl amino oxides, while the acidic agents were classified as chemicals with no environmental impact. The enzymatic agent contained an enzyme that was acutely toxic to aquatic organisms. Although the acid and alkaline cleaners in this study showed a similar degree of effect on biofilms, and the latter is more toxic to the environment, one cannot deduce that the food industry should move from alkaline to acidic cleaners in general. For many food processes, the removal of fat or starch is important, and then alkaline cleaners are more effective [3].

\section{Conclusions}

The study supported experiences from the industry showing that Listeria monocytogenes biofilms formed on conveyor belt materials are difficult to remove through regular cleaning and disinfection. Both increasing concentrations and combining acidic and alkaline cleaning agents seemed promising for the removal of L. monocytogenes biofilms in niches that are difficult to reach for mechanical action. In addition, applying an alcohol disinfectant after thorough cleaning was efficient for eliminating biofilms.

Author Contributions: Formal analysis; investigation; visualization: A.F.; project administration; supervision; validation: A.F. and S.L.; writing —original draft preparation: A.F., E.H., and S.L.; conceptualization; methodology; writing-review and editing: A.F., E.H., T.M., and S.L. All authors have read and agreed to the published version of the manuscript.

Funding: This work was supported by Norwegian Research Funding for Agriculture and Food Industry, grant numbers 221663 and 262306. The APC was funded by Nofima.

Acknowledgments: The authors thank Tove Maugesten and Charlotte Nilsen for their excellent technical assistance.

Conflicts of Interest: The authors declare no conflict of interest.

\section{References}

1. Gibson, H.; Taylor, J.H.; Hall, K.E.; Holah, J.T. Effectiveness of cleaning techniques used in the food industry in terms of removal of bacterial biofilms. J. Appl. Microbiol. 1999, 87, 41-48. [CrossRef]

2. Fukuzaki, S. Mechanisms of actions of sodium hypochlorite in cleaning and disinfection processes. Biocontrol. Sci. 2006, 11, 147-157. [CrossRef] [PubMed]

3. Stanga, M. Sanitation: Cleaning and disinfection in the food industry; Wiley-VCH: Weinheim, Germany, 2010. 
4. Urano, H.; Fukuzaki, S. The mode of action of hypochlorite in the cleaning process. Biocontrol. Sci. 2005, 10, 21-29. [CrossRef]

5. Møretrø, T.; Langsrud, S. Residential bacteria on surfaces in the food industry and their implications for food safety and quality. Compr. Rev. Food Sci. Food Saf. 2017, 16, 1022-1041. [CrossRef]

6. Carpentier, B.; Cerf, O. Review-Persistence of Listeria monocytogenes in food industry equipment and premises. Int. J. Food Microbiol. 2011, 145, 1-8. [CrossRef] [PubMed]

7. Ferreira, V.; Wiedmann, M.; Teixeira, P.; Stasiewicz, M.J. Listeria monocytogenes persistence in food-associated environments: Epidemiology, strain characteristics, and implications for public health. J. Food Prot. 2014, 77, 150-170. [CrossRef]

8. $\quad$ Larsen, M.H.; Dalmasso, M.; Ingmer, H.; Langsrud, S.; Malakauskas, M.; Mader, A.; Møretrø, T.; Mozina, S.S.; Rychli, K.; Wagner, M.; et al. Persistence of foodborne pathogens and their control in primary and secondary food production chains. Food Control 2014, 44, 92-109. [CrossRef]

9. Tompkin, R.B. Control of Listeria monocytogenes in the food-processing environment. J. Food Prot. 2002, 65, 709-725. [CrossRef]

10. Colagiorgi, A.; Bruini, I.; Di Ciccio, P.A.; Zanardi, E.; Ghidini, S.; Ianieri, A. Listeria monocytogenes biofilms in the wonderland of food industry. Pathogens 2017, 6, 41. [CrossRef]

11. Lappi, V.R.; Thimothe, J.; Nightingale, K.K.; Gall, K.; Scott, V.N.; Wiedmann, M. Longitudinal studies on Listeria in smoked fish plants: Impact of intervention strategies on contamination patterns. J. Food Prot. 2004, 67, 2500-2514. [CrossRef]

12. Codex Alimentarius Commission. Guidelines on the application of general principles of food hygiene to the control of Listeria monocytogenes in foods. CAC/GL 61. 2007. Available online: http://www.fao.org/input/ download/standards/10740/CXG_061e.pdf (accessed on 12 February 2020).

13. U.S. Department of Agriculture, Food Safety and Inspection Service. FSIS Compliance Guideline: Controlling Listeria monocytogenes in Post-Lethality Exposed Ready-to-Eat Meat and Poultry Products. 2014. Available online: https://www.fsis.usda.gov/wps/wcm/connect/d3373299-50e6-47d6-a577-e74a1e549fde/ControllingLm-RTE-Guideline.pdf?MOD=AJPERES (accessed on 12 February 2020).

14. Fagerlund, A.; Møretrø, T.; Heir, E.; Briandet, R.; Langsrud, S. Cleaning and disinfection of biofilms composed of Listeria monocytogenes and background microbiota from meat processing surfaces. Appl. Environ. Microbiol. 2017, 83, 01046-17. [CrossRef] [PubMed]

15. Chaturongkasumrit, Y.; Takahashi, H.; Keeratipibul, S.; Kuda, T.; Kimura, B. The effect of polyesterurethane belt surface roughness on Listeria monocytogenes biofilm formation and its cleaning efficiency. Food Control 2011, 22, 1893-1899. [CrossRef]

16. Goode, K.R.; Asteriadou, K.; Robbins, P.T.; Fryer, P.J. Fouling and cleaning studies in the food and beverage industry classified by cleaning type. Compr. Rev. Food Sci. Food Saf. 2013, 12, 121-143. [CrossRef]

17. Bredholt, S.; Maukonen, J.; Kujanpaa, K.; Alanko, T.; Olofson, U.; Husmark, U.; Sjøberg, A.; Wirtanen, G. Microbial methods for assessment of cleaning and disinfection of food-processing surfaces cleaned in low-pressure system. Eur. Food Res. Technol. 1999, 209, 145-152. [CrossRef]

18. Leriche, V.; Briandet, R.; Carpentier, B. Ecology of mixed biofilms subjected daily to a chlorinated alkaline solution: Spatial distribution of bacterial species suggests a protective effect of one species to another. Environ. Microbiol. 2003, 5, 64-71. [CrossRef]

19. Wirtanen, G.; Husmark, U.; Mattila-Sandholm, T. Microbial evaluation of the biotransfer potential from surfaces with Bacillus biofilms after rinsing and cleaning procedures in closed food-processing systems. J. Food Prot. 1996, 59, 727-733. [CrossRef]

20. Simões, M.; Pereira, M.O.; Vieira, M.J. Effect of mechanical stress on biofilms challenged by different chemicals. Water Res. 2005, 39, 5142-5152. [CrossRef]

21. Reynisson, E.; Guðbjörnsdóttir, B.; Marteinsson, V.P.; Hreggviðsson, G.O. Decontamination efficiency of fish bacterial flora from processing surfaces. Food Technol. Biotechnol. 2009, 47, 75-82.

22. Puga, C.H.; Rodríguez-López, P.; Cabo, M.L.; SanJose, C.; Orgaz, B. Enzymatic dispersal of dual-species biofilms carrying Listeria monocytogenes and other associated food industry bacteria. Food Control 2018, 94, 222-228. [CrossRef]

23. Meireles, A.; Borges, A.; Giaouris, E.; Simões, M. The current knowledge on the application of anti-biofilm enzymes in the food industry. Food Res. Int. 2016, 86, 140-146. [CrossRef] 
24. Nguyen, U.T.; Burrows, L.L. DNase I and proteinase K impair Listeria monocytogenes biofilm formation and induce dispersal of pre-existing biofilms. Int. J. Food Microbiol. 2014, 187, 26-32. [CrossRef] [PubMed]

25. Okshevsky, M.; Meyer, R.L. The role of extracellular DNA in the establishment, maintenance and perpetuation of bacterial biofilms. Crit. Rev. Microbiol. 2015, 41, 341-352. [CrossRef] [PubMed]

26. Kaplan, J.B.; Ragunath, C.; Velliyagounder, K.; Fine, D.H.; Ramasubbu, N. Enzymatic detachment of Staphylococcus epidermidis biofilms. Antimicrob. Agents Chemother. 2004, 48, 2633-2636. [CrossRef]

27. Lu, T.K.; Collins, J.J. Dispersing biofilms with engineered enzymatic bacteriophage. Proc. Natl. Acad. Sci. USA 2007, 104, 11197-11202. [CrossRef]

28. Kiedrowski, M.R.; Horswill, A.R. New approaches for treating staphylococcal biofilm infections. Ann. New York Acad. Sci. 2011, 1241, 104-121. [CrossRef]

29. Thallinger, B.; Prasetyo, E.N.; Nyanhongo, G.S.; Guebitz, G.M. Antimicrobial enzymes: An emerging strategy to fight microbes and microbial biofilms. Biotechnol. J. 2013, 8, 97-109. [CrossRef]

30. Araújo, P.A.; Machado, I.; Meireles, A.; Leiknes, T.; Mergulhão, F.; Melo, L.F.; Simões, M. Combination of selected enzymes with cetyltrimethylammonium bromide in biofilm inactivation, removal and regrowth. Food Res. Int. 2017, 95, 101-107. [CrossRef]

31. Møretrø, T.; Schirmer, B.C.T.; Heir, E.; Fagerlund, A.; Hjemli, P.; Langsrud, S. Tolerance to quaternary ammonium compound disinfectants may enhance growth of Listeria monocytogenes in the food industry. Int. J. Food Microbiol. 2017, 241, 215-224. [CrossRef]

32. Overney, A.; Jacques-André-Coquin, J.; Ng, P.; Carpentier, B.; Guillier, L.; Firmesse, O. Impact of environmental factors on the culturability and viability of Listeria monocytogenes under conditions encountered in food processing plants. Int. J. Food Microbiol. 2017, 244, 74-81. [CrossRef]

33. Pan, Y.; Breidt, F., Jr.; Kathariou, S. Resistance of Listeria monocytogenes biofilms to sanitizing agents in a simulated food processing environment. Appl. Environ. Microbiol. 2006, 72, 7711-7717. [CrossRef]

34. Rodriguez-Lopez, P.; Carballo-Justo, A.; Draper, L.A.; Cabo, M.L. Removal of Listeria monocytogenes dual-species biofilms using combined enzyme-benzalkonium chloride treatments. Biofouling 2017, 33, 45-58. [CrossRef]

35. Arizcun, C.; Vasseur, C.; Labadie, J.C. Effect of several decontamination procedures on Listeria monocytogenes growing in biofilms. J. Food Prot. 1998, 61, 731-734. [CrossRef] 